
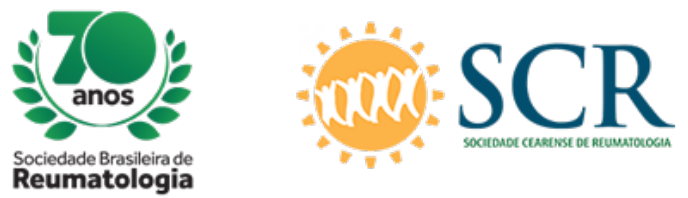

\title{
IS PROLONGED RANITIDINE USE ASSOCIATED WITH LOW RECURRENT ABDOMINAL PAIN IN IGA VASCULITIS?
}

Izabel Montovani Buscatti (Instituto da Criança e do Adolescente HC-FMUSP, São Paulo, SP, Brasil), Juliana Russo Simon (Instituto da Criança e do Adolescente HC-FMUSP, São Paulo, SP, Brasil), Vitor Cavalcanti Trindade (Instituto da Criança e do Adolescente HC-FMUSP, São Paulo, SP, Brasil), Tamima Mohamad Arabi (Instituto da Criança e do Adolescente HC-FMUSP, São Paulo, SP, Brasil), Ana Carolina

Maia (Instituto da Criança e do Adolescente HC-FMUSP, São Paulo, SP, Brasil), Lara Regina Melo

(Instituto da Criança e do Adolescente HC-FMUSP, São Paulo, SP, Brasil), Vivianne Saraiva Viana (Instituto da Criança e do Adolescente HC-FMUSP, São Paulo, SP, Brasil), Bianca Pires Ihara (Instituto da Criança e do Adolescente HC-FMUSP, São Paulo, SP, Brasil), Katia Tomie Kozu (Instituto da Criança e do Adolescente HC-FMUSP, São Paulo, SP, Brasil), Nadia Emi Aikawa (Instituto da Criança e do Adolescente HC-FMUSP, São Paulo, SP, Brasil), Clovis Artur Silva (Instituto da Criança e do Adolescente HC-FMUSP, São Paulo, SP, Brasil)

\section{BACKGROUND}

The most frequent systemic vasculitis of small vessels in childhood is Immunoglobulin A(IgA) vasculitis. The presence and intensity of abdominal pain and other gastrointestinal(GI) manifestations are criteria for both disease classification and treatment with corticosteroids. However, to our knowledge, there is no study evaluating recurrent abdominal pain associated with IgA vasculitis. Therefore, the objectives were to assess recurrent abdominal pain in IgA vasculitis patients and its relation between demographic data, clinical manifestations, and treatments.

\section{MATERIALS AND METHODS}

A cross-sectional retrospective study included 322 patients with IgA vasculitis(EULAR/PRINTO/PRES criteria) followed at the Pediatric Rheumatology Unit for 32 consecutive years. Sixteen patients were excluded due to incomplete data in medical charts. Recurrent abdominal pain was characterized by new abdominal pain after complete resolution.

\section{RESULTS}

Recurrent abdominal pain was observed in 35/306(11\%) in IgA vasculitis patients. The main treatment of recurrent abdominal pain included glucocorticosteroid[ $n=26 / 35(74 \%)]$ and/or ranitidine[ $n=22 / 35(63 \%)]$. Additional analysis showed that the frequency of recurrent purpura/petechiae ( $37 \%$ vs. $21 \%, p=0.027)$ and the median of purpura/petechiae duration [20(3-90) vs. 14(1-270) days, $p=0.014]$ were significantly higher in IgA vasculitis patients with recurrent abdominal pain compared to those without this complication. Gastrointestinal bleeding( $49 \%$ vs. $13 \%, p<0.001)$, nephritis $(71 \%$ vs. $45 \%, p=0.006)$, glucocorticosteroid use( $74 \%$ vs. $44 \%, p=0.001)$ and intravenous immunoglobulin( $6 \%$ vs. $0 \%, p=0.036)$ were also significantly higher in the former group. The frequency of ranitidine use was significantly higher in IgA vasculitis patients with recurrent abdominal pain versus without(63\% vs. $28 \%, p<0.001)$, whereas the ranitidine duration was reduced in the former group[35(2-90) vs. 60(5-425) days, $p=0.004]$.

\section{CONCLUSION}

Recurrent abdominal pain occurred in a low frequency on IgA vasculitis patients and was associated with severe clinical features. Our study suggests that ranitidine should promptly be used more than two months in IgA vasculitis with abdominal pain. Further prospective studies will be necessary to clarify this issue. 